\title{
Simultaneous Estimation of Gliflozin Derivatives Canagliflozin, Dapagliflozin, Empagliflozin and Ertugliflozin Using RP-HPLC Methods
}

\section{Arulselvan Murugesan ${ }^{1 *}$ and Annapurna Mukthinuthalapati Mathrusri $^{2}$}

${ }^{1}$ Department of Pharmaceutical Analysis, AIKTC School of Pharmacy, New Panvel

Dist-Raigad (M.S.), India

${ }^{2}$ Department of Pharmaceutical Analysis and Quality Assurance, GITAM Institute of

Pharmacy, GITAM (Deemed to be University), Visakhapatnam, India

*Corresponding Author: Arulselvan Murugesan, Department of Pharmaceutical

Analysis, AIKTC School of Pharmacy, New Panvel Dist-Raigad (M.S.), India.
Received: November 30, 2020

Published: December 07, 2021

(C) All rights are reserved by Arulselvan

Murugesan and Annapurna

Mukthinuthalapati Mathrusri.

\section{Abstract}

A reliable, simple, precise, stability indicating reverse phase HPLC method was developed to study simultaneous estimation of Gliflozin derivatives like Canagliflozin, Dapagliflozin, Empagliflozin and Ertugliflozin. Focus of our study is to quantify the derivatives with freely available non expensive solvent systems within a short period of time. The chromatographic separation obtained by using Inertsil ODS column ( $25 \mathrm{~cm} \times 46 \mathrm{~mm}) \times 5 \mu \mathrm{m}$ internal diameter with isocratic flow. The mobile phase TEA: ACN pH (50:50) at a flow rate $1 \mathrm{ml} / \mathrm{min}$. The analytes were detected by using a UV detector at $260 \mathrm{~nm}$. Forced degradation studies for gliflozin derivatives conducted as per the ICH guidelines and the resulting degrades were characterized by its peak area at its retention time as per the proposed method. The system suitability results support the proposed method elutes the analytes with good resolution within 10 min in a repeatable manner. The linearity value observed with the concentration range of 30-450 $\mu \mathrm{g} / \mathrm{mL}$ for Canagliflozin, 1-15 $\mu \mathrm{g} /$ mL for Dapagliflozin, 2.5 to $37.50 \mu \mathrm{g} / \mathrm{mL}$ for Empagliflozin and 0.5 to $7.5 \mu \mathrm{g} / \mathrm{mL}$ for Ertugliflozin and its calibration curve value found to be $\mathrm{y}=25151 \mathrm{x}+40130\left(\mathrm{r}^{2}=0.9991\right), \mathrm{y}=109655 \mathrm{x}+8166\left(\mathrm{r}^{2}=0.9989\right), \mathrm{y}=73755 \mathrm{x}+636\left(\mathrm{r}^{2}=0.9998\right), \mathrm{y}=169230 \mathrm{x}+8269\left(\mathrm{r}^{2}\right.$ $=0.9997$ ) respectively. The percentage recovery of the drugs found to be 100.2-100.4, 99.7-100.6, 99.5-99.7, 99.6-100.03 for 50\%, $100 \%$ and $150 \%$ and these results are within acceptable limits. In this developed method the separated analyte peak found to be sharp, specific, reproducible, and robust in all the studies conducted in repeatable process. Forced degradation studies involved in studying the drug stability in different stress conditions and to identify the degradants of the drug products. The validated method found precise in forced degradation studies conditions and found less than $10 \%$ degradation products in this study. The developed and validated method proved that the proposed method was simple, reliable, highly specific and stability indicating for gliflozin derivatives based on its statistical data obtained with its peak area and relevant factors. Hence, this method might be applied for simultaneous estimation of all these drugs in pharmaceutical formulation.

Keywords: Canagliflozin; SGLT2; T2DM; Dapagliflozin; Empagliflozin; Ertugliflozin; RP HPLC; Forced Degradation

\section{Introduction}

Near to $6.28 \%$ number of the population suffered from Type 2 Diabetic mellitus as per the 2017 report which must be considered as a life threatening and cause remarkable changes in social and health care systems of human race. Treating patients suffering with Type 2 diabetes mellitus need drug therapy with improved changes in lifestyle pattern like proper diet, exercise, and prescribed lifestyle [1].

In T2DM drug therapy treating patients with SGLT found to be recurrent and positive in the patients and volunteers participated 
in clinical trials. Gliflozin derivatives reduce the blood glucose level in patients by reducing glucose reabsorption by kidney and improve urinary excretion of glucose for the suffering with Type 2 diabetic mellitus. In diabetic type 2 blood glucose level was found more and it is due to $90 \%$ absorption of glucose by SGLT, inhibiting them by gliflozin reduces the level which is highly recommended therapy nowadays [2-4].

Canagliflozin $\left(\mathrm{C}_{24} \mathrm{H}_{25} \mathrm{FO}_{5} \mathrm{~S}\right)$ is chemically named as (2S,3R,4R,5S,6R) -2- [3- [[5-(4-fluoro phenyl) thiophen-2-yl] methyl]-4-methylphenyl]-6-(hydroxymethyl) oxane-3,4,5-triol; hydrate with physical appearance of white to off white solid with melting range of $95-105^{\circ} \mathrm{C}$ [5]. Canagliflozin is a novel oral antidiabetic agent and the first SGLT2 inhibitor approved for glycemic control in adults with T2DM. U.S. Food and Drug Administration (US FDA) approved this drug in March-2013 for treating the patients having type-II diabetes $[9,10]$.

Dapagliflozin $\left(\mathrm{C}_{21} \mathrm{H}_{25} \mathrm{ClO}_{6}\right)$ is chemically named as (1S)-1, 5-anhydro- 1-C-[4-chloro-3-[(4-ethoxyphenyl) methyl] phenyl]-Dglucitol, physical appearance of it is a white to off white solid with melting range of $74-78{ }^{\circ} \mathrm{C}$. The molecular weight is $408.873 \mathrm{~g} /$ mol [6]. Dapagliflozin is a C-glycosyl comprising beta-D-glucose in which the anomeric hydroxyl group is replaced by a 4-chloro-3-(4ethoxybenzyl) phenyl group to improve glycemic control in adults with type 2 diabetes along with improved lifestyle. Adults with proper diet and exercise showed improved glycemic control during treatment $[11,12]$.

Empagliflozin $\left(\mathrm{C}_{23} \mathrm{H}_{27} \mathrm{ClO}_{7}\right)$ gliflozin derivative, chemically called as $(2 \mathrm{~S}, 3 \mathrm{R}, 4 \mathrm{R}, 5 \mathrm{~S}, 6 \mathrm{R})-2-[4$-chloro-3-[[4-[(3S)-oxolan-3-yl] oxy phenyl] methyl] phenyl]-6-(hydroxy methyl) oxane-3, 4, 5-triol [7]. Empagliflozin by its independent hypoglycemic mechanism protects the diabetic patients suffering with cardiac and kidney disorder $[13,14]$. Empagliflozin with combination therapy produces positive results among T2DM patients.

Ertugliflozin $\left[\mathrm{C}_{22} \mathrm{H}_{25} \mathrm{ClO}_{7}\right]$ chemically called as $(1 \mathrm{~S}, 2 \mathrm{~S}, 3 \mathrm{~S}, 4 \mathrm{R}, 5 \mathrm{~S})$ 5-(4-chloro-3-(4-ethoxybenzyl) phenyl)-1-(hydroxymethyl)-6,8dioxabicyclo [3.2.1] octane-2,3,4-triol [8]. Ertugliflozin and fixeddose combinations of Ertugliflozin and Metformin, Ertugliflozin and sitagliptin have recently been approved by the US FDA as an adjunct to diet and exercise to improve glycemic control in adults with T2DM [15-17] The structure of Canagliflozin, Dapagliflozin, Empagliflozin and Ertugliflozin was shown in figure 1.
Various analytical reports submitted for gliflozin derivatives with combination of more than 2 drugs or gliflozin derivatives with Metformin using RP-HPLC methods. Current study focused on identifying the relationship between weakly ionizable gliflozin drugs and its separation properties in buffer pH 3-6 [17-21].<smiles>CC(=O)NOC(C)=O</smiles><smiles>CCOc1ccc(Cc2cc([C@@H]3O[C@H](CO)[C@@H](O)[C@H](O)[C@H]3O)ccc2Cl)cc1</smiles><smiles>CCCCCCCCCCON</smiles><smiles>CCOc1ccc(Cc2cc([C@]34OC[C@](CO)(O3)[C@@H](O)[C@@H](O)[C@H]4O)ccc2Cl)cc1</smiles>

Figure 1: Chemical Structure of A. Canagliflozin, B. Dapagliflozin, C. Empagliflozin and D. Ertugliflozin.

\section{Methods and Materials}

\section{Instrumentation}

Waters HPLC system consisted of a Quaternary pump, Rheodyne injector with PDA detector used for our developed method. 
Agilent HPLC system made up of Quaternary pump, Auto injector with G1315B detector used for Intermediate precision study. Empower 2.0 software, collected, and compiled the chromatographic data obtained for Gliflozin derivatives in both the HPLC systems. Zorbax C18 and Inertsil ODS column is used for separation through isocratic elution.

\section{Chemical and reagent}

For this proposed method HPLC grade Acetonitrile, Triethylamine and HPLC grade distilled water procured from Loba Chemie Pvt Ltd, India. Working standards of Canagliflozin, Dapagliflozin, Empagliflozin and Ertugliflozin were purchased from Supriya Life science Ltd, India.

Chromatographic parameters

Equipment: Waters, Alliance Model 2695

Wavelength: $232 \mathrm{~nm}$

Injection volume : $10 \mu \mathrm{L}$.

Flow rate: $01 \mathrm{~mL} /$ minute.

Run time: 6 Minutes.

Column: ZORBAX C ${ }_{18}(250 \times 4.6 \mathrm{~mm}, 5 \mu \mathrm{m}$ particle size $)$

Mobile Phase: Acetate buffer (pH 3.4): Acetonitrile (60:40)

Oven Temperature: $28^{\circ} \mathrm{C}$.

Preparation of mobile phase

Mix Triethylamine with Acetonitrile in the ratio of 60:40 and adjust the $\mathrm{pH}$ to 2.5 by using $0.1 \%$ Ortho phosphoric acid. Degas the mobile phase before use and sonicate the mobile reservoir for 20 minutes before injection.

\section{Preparation of standard solution}

Accurately weighed $300 \mathrm{mg}$ of Canagliflozin, $10 \mathrm{mg}$ of Dapagliflozin, $25 \mathrm{mg}$ of Empagliflozin and $5 \mathrm{mg}$ of Ertugliflozin working standards are taken into $100 \mathrm{~mL}$ volumetric flask, add $70 \mathrm{~mL}$ of Mobile phase, sonicated for $10 \mathrm{~min}$ to dissolve the contents, and made up to the mark with mobile phase. Further dilute $5 \mathrm{~mL}$ of above solution to $50 \mathrm{~mL}$ volumetric flask with diluent.

\section{Preparation of sample solution}

20 Tablets of Canagliflozin, Dapagliflozin, Empagliflozin and Ertugliflozin were crushed into powder form. Accurately weighed tablet equivalent of $372 \mathrm{mg}$ of Canagliflozin sample (each tablet contains $300 \mathrm{mg}$ of Canagliflozin), $39 \mathrm{mg}$ of Dapagliflozin sample (each tablet contains $10 \mathrm{mg}$ of Dapagliflozin), $64 \mathrm{mg}$ of Empagliflozin sample (each tablet contains $25 \mathrm{mg}$ of Empagliflozin) and $58 \mathrm{mg}$ of Ertugliflozin sample (each tablet contains $5 \mathrm{mg}$ of Ertugliflozin) were transferred into $100 \mathrm{ml}$ volumetric flask, added 70 $\mathrm{ml}$ of mobile phase, sonicated it for $30 \mathrm{~min}$ to dissolve the contents. Finally make the volume up to mark using mobile phase as diluent. Further dilute $5 \mathrm{~mL}$ of above solution to $50 \mathrm{~mL}$ volumetric flask with diluent.

\section{Validation}

Validation performed as per the guidelines provided by ICH guidelines. Validation parameters performed for the proposed methods were linearity, precision, accuracy, robustness and forced degradation study $[22,23]$.

\section{Linearity}

Linear test reading was conducted by preparing standard solution of different concentrations range $30-450 \mu \mathrm{g} / \mathrm{mL}$ for Canagliflozin, 1-15 $\mu \mathrm{g} / \mathrm{mL}$ for Dapagliflozin, 2.5 to $37.50 \mu \mathrm{g} / \mathrm{mL}$ for Empagliflozin and 0.5 to $7.5 \mu \mathrm{g} / \mathrm{mL}$ for Ertugliflozin by transferring 0.5 to $7.5 \mathrm{~mL}$ of stock solution into $50 \mathrm{~mL}$ volumetric flask. Make the volume with mobile phase and inject $10 \mu \mathrm{L}$ triplicate solutions of different concentrations into the HPLC system.

\section{Precision}

Intermediate and Method Precision was conducted as per the procedure and ICH guidelines. In Intermediate and Method precision, the sample of same concentration of different analyte like 300 $\mu \mathrm{g}$ of Canagliflozin, $10 \mu \mathrm{g}$ of Dapagliflozin, $25 \mu \mathrm{g}$ of Empagliflozin and $5 \mu \mathrm{g}$ of Ertugliflozin were injected into 2 different systems at 6 different time intervals within a day and on alternate days.

\section{Accuracy}

The percentage recovery study was performed by injecting different concentrations of Canagliflozin, Dapagliflozin, Empagliflozin and Ertugliflozin with 50\%, 100\% and 150\%. The percentage of recovery of gliflozin derivatives was estimated by considering peak area of spiked concentration versus peak area of standard concentration.

\section{Robustness}

Deliberate changes or deliberate variation of the proposed method was conducted by introducing minor changes in various 
chromatographic parameters such as flow rate, mobile phase composition, detection wavelength and column temperature.

System suitability

System suitability for the proposed method is evaluated by injecting the working standard of Gliflozin derivatives into the system with the same concentration six times and analyzing its peak area.

\section{Forced degradation studies}

Acid degradation

Accurately weighed $372 \mathrm{mg}$ of Canagliflozin, $39 \mathrm{mg}$ of Dapagliflozin, $64 \mathrm{mg}$ of Empagliflozin and $58 \mathrm{mg}$ of Ertugliflozin sample and transferred it into a $100 \mathrm{ml}$ volumetric flask. Added $70 \mathrm{~mL}$ of diluents sonicated for $15 \mathrm{~min}$ to dissolve the contents, diluted to volume with using diluent. To $1 \mathrm{~mL}$ of above stock solution added $1 \mathrm{~mL}$ of $0.1 \mathrm{~N} \mathrm{HCl}$. Sonicate it for $15 \mathrm{~min}$ and then add $1 \mathrm{~mL}$ of $0.1 \mathrm{~N}$ $\mathrm{NaOH}$ to neutralize the solution. Same procedures followed for $1 \mathrm{~N}$ by diluting it with $0.1 \mathrm{~N} \mathrm{HCl}$ utilized $01 \mathrm{~N} \mathrm{HCl}$.

\section{Alkali degradation}

Accurately weighed $372 \mathrm{mg}$ of Canagliflozin, $39 \mathrm{mg}$ of Dapagliflozin, $64 \mathrm{mg}$ of Empagliflozin and $58 \mathrm{mg}$ of Ertugliflozin sample and transferred into a $100 \mathrm{ml}$ volumetric flask. Added $70 \mathrm{~mL}$ of diluents sonicated for $15 \mathrm{~min}$ to dissolve the contents, diluted to volume with diluent. To $1 \mathrm{~mL}$ of above stock solution added $1 \mathrm{~mL}$ of $0.1 \mathrm{~N} \mathrm{NaOH}$. Sonicate it for $15 \mathrm{~min}$ and then add $1 \mathrm{~mL}$ of $0.1 \mathrm{~N} \mathrm{HCl}$ to neutralize the solution. Same procedures followed for $1 \mathrm{~N}$ by diluting it with $0.1 \mathrm{~N} \mathrm{NaOH}$ utilized $01 \mathrm{~N} \mathrm{NaOH}$.

\section{Peroxide degradation}

Accurately weighed $372 \mathrm{mg}$ of Canagliflozin, $39 \mathrm{mg}$ of Dapagliflozin, $64 \mathrm{mg}$ of Empagliflozin and $58 \mathrm{mg}$ of Ertugliflozin sample and transferred it into a $100 \mathrm{~mL}$ volumetric flask. Added $70 \mathrm{~mL}$ of diluents sonicated for $15 \mathrm{~min}$ to dissolve the contents, diluted to volume with diluent. To $1 \mathrm{~mL}$ of above stock solution add $1 \mathrm{~mL}$ of $10 \% \mathrm{H}_{2} \mathrm{O}_{2}$ and diluted to volume with diluent and mixed. Same procedures followed for $1 \mathrm{~N}$ by diluting it with $30 \% \mathrm{H}_{2} \mathrm{O}_{2}$ instead of $10 \% \mathrm{H}_{2} \mathrm{O}_{2}$.

\section{Reduction degradation}

Accurately weighed $372 \mathrm{mg}$ of Canagliflozin, $39 \mathrm{mg}$ of Dapagliflozin, $64 \mathrm{mg}$ of Empagliflozin and $58 \mathrm{mg}$ of Ertugliflozin sample and transferred into a $100 \mathrm{~mL}$ volumetric flask. Added $70 \mathrm{~mL}$ of diluents sonicated for $15 \mathrm{~min}$ to dissolve the contents, diluted to volume with diluent. To $1 \mathrm{~mL}$ of above stock solution added $1 \mathrm{ml}$ of $10 \%$ sodium bi sulphate and diluted to volume with diluent and mixed. Same procedures followed for $1 \mathrm{~N}$ by diluting it with $30 \%$ $\mathrm{NaHSO}_{4}$ instead of $10 \% \mathrm{NaHSO}_{4}$.

\section{Thermal degradation}

Weighed sample of $500 \mathrm{mg}$ of Canagliflozin, $100 \mathrm{mg}$ of Dapagliflozin, $100 \mathrm{mg}$ of Empagliflozin and $100 \mathrm{mg}$ of Ertugliflozin was exposed at $105{ }^{\circ} \mathrm{C}$ for $3 \mathrm{~h}$ and the exposed sample was analyzed. Same procedures followed for $1 \mathrm{~N}$ by exposing it for $6 \mathrm{~h}$ instead of $3 \mathrm{~h}$.

\section{Photolytic degradation}

Weighed sample of $500 \mathrm{mg}$ of Canagliflozin, $100 \mathrm{mg}$ of Dapagliflozin, $100 \mathrm{mg}$ of Empagliflozin and $100 \mathrm{mg}$ of Ertugliflozin sample was exposed to sunlight for 3 hours. and the exposed sample was analyzed. Same procedures followed for $1 \mathrm{~N}$ by exposing it for $6 \mathrm{~h}$ instead of $3 \mathrm{~h}$.

\section{Hydrolysis degradation}

Accurately weighed $372 \mathrm{mg}$ of Canagliflozin, $39 \mathrm{mg}$ of Dapagliflozin, $64 \mathrm{mg}$ of Empagliflozin and $58 \mathrm{mg}$ of Ertugliflozin sample and transferred into a $100 \mathrm{ml}$ volumetric flask. Added $70 \mathrm{ml}$ of diluents sonicated for $15 \mathrm{~min}$ to dissolve the contents, diluted to volume with diluent. After dissolving the content take $1 \mathrm{~mL}$ of above stock solution and then add $5 \mathrm{ml}$ of water and diluted to volume with diluent and mixed for properly dissolving the drug. Same procedures followed for $1 \mathrm{~N}$ by diluting it with $10 \mathrm{~mL}$ water instead of $5 \mathrm{~mL}$ water.

\section{Results and Discussion}

\section{Selection of mobile phase}

For this study we utilize different mobile phases with different mobile phase composition. Gliflozin derivatives are found to be weakly ionizable in nature so that we reduce that mobile phase selection by selecting buffer samples solution with $\mathrm{pH} 2$ to $\mathrm{pH} 5$. Buffer samples with $\mathrm{pH} 2.5$ to 3.5 found most promising in eluting the drug with good resolution and peak area and for this study we utilize Triethylamine buffer solution with acetonitrile in ratio of 50:50. 


\section{Selection of wavelength}

Identification of analytical wavelength for Gliflozin derivatives involved in identifying the wavelength where we will get a good amount of absorption. Trial run conducted at wavelength near to 200 to $400 \mathrm{~nm}$ to identify the $\lambda$ max for gliflozin derivatives. After different trials we found that $260 \mathrm{~nm}$ is the $\lambda \max$ for simultaneous estimation of gliflozin derivative.

\section{Selection of column and column temperature}

The column with different nature includes C18, C8 with different size $25 \mathrm{~cm}, 15 \mathrm{~cm}$ were studied for this developed method. Column size and its effective column temperature are involved in separating the gliflozin derivatives, with good amount of resolution and even in minimal concentration range of drugs. Column with 25 $\mathrm{cm}$ size, internal diameter $5 \mu \mathrm{m}$ found to separate the analytes with good resolution at ambient temperature.

The proposed method Elute the analytes with good percentage of peak area resolution for various analytical parameters at

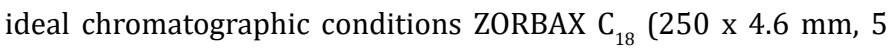
$\mu \mathrm{m}$ particle size) ambient temperature, buffer $\mathrm{pH}$ adjusted to 2.5 with $0.1 \%$ OPA: Acetonitrile 50:50 ratio and the flow rate $1 \mathrm{~mL} /$ min conducted as per ICH guidelines.

\section{Method validation}

Linearity

The calibration curve found to be linear (Figure 2 and Figure 3) for Canagliflozin Dapagliflozin, Empagliflozin and Ertugliflozin with concentration range of 30-450 $\mu \mathrm{g} / \mathrm{mL}$ for Canagliflozin, 1-15 $\mu \mathrm{g} / \mathrm{mL}$ for Dapagliflozin, 2.5 to $37.50 \mu \mathrm{g} / \mathrm{mL}$ for Empagliflozin and 0.5 to $7.5 \mu \mathrm{g} / \mathrm{mL}$ for Ertugliflozin. The correlation coefficient of regression value, concentration and intercept value was calculated using the formula $\mathrm{y}=25151 \mathrm{x}+40131\left(\mathrm{r}^{2}=0.9991\right), \mathrm{y}=$ $109655 x+8166\left(r^{2}=0.9989\right), y=73756 x+6364\left(r^{2}=0.9998\right)$ and $y=169230 x+8269\left(r^{2}=0.9997\right)$ for Canagliflozin, Dapagliflozin, Empagliflozin and Ertugliflozin respectively and summarized in table 1.

\section{Mean peak area of three replicates}

Accuracy

The \% Mean recovery for Canagliflozin, Dapagliflozin, Empagliflozin and Ertugliflozin was found to be 100.2-100.4, 99.7-100.6, 99.5-99.7, 99.6-100.03 for $50 \%, 100 \%$ and $150 \%$ and these results
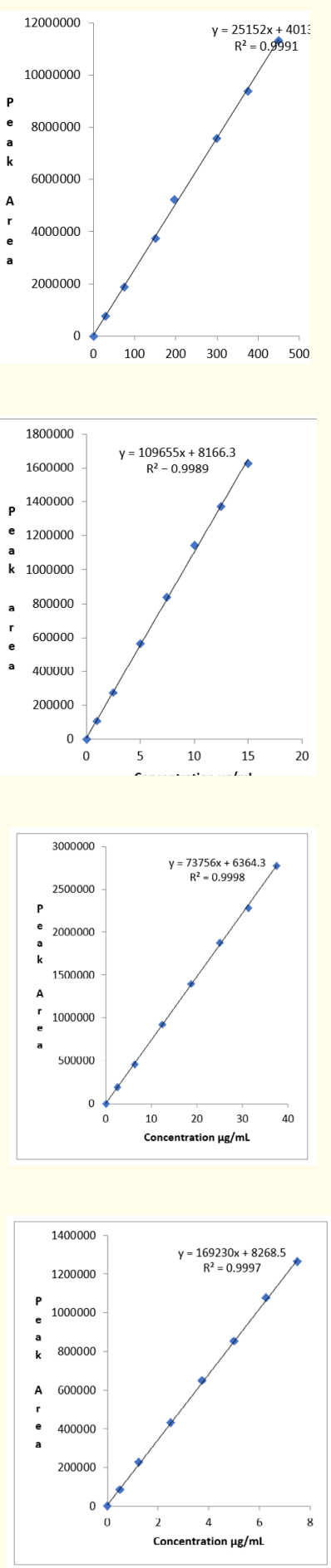

Figure 2: Calibration Curve of Canagliflozin, Dapagliflozin, Empagliflozin and Ertugliflozin. 


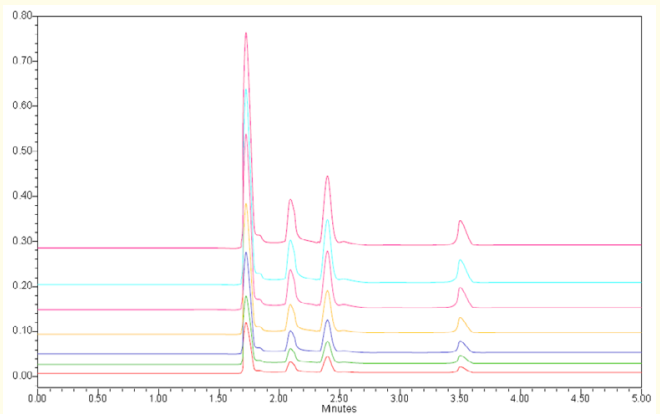

Figure 3: Linearity chromatogram peaks of Canagliflozin, Dapagliflozin, Empagliflozin and Ertugliflozin (L to R).

are within acceptable limits. The \% RSD for Gliflozin derivatives were found within limit of $\leq 2$ and its high value of recoveries at $50 \%$, $100 \%$ and $150 \%$ concentrations indicate the performed method is accurate. The accuracy data of the proposed method is summarized in table $2 \mathrm{~A}$.

\begin{tabular}{|l|c|c|c|c|}
\hline \multirow{2}{*}{ S. No } & \multicolumn{4}{|c|}{ *Mean Peak area } \\
\cline { 2 - 5 } & Canagliflozin & Dapagliflozin & Empagliflozin & Ertugliflozin \\
\hline 1 & 0 & 0 & 0 & 0 \\
\hline 2 & 768241 & 107356 & 199101 & 87738 \\
\hline 3 & 1861715 & 277356 & 454301 & 229337 \\
\hline 4 & 3763987 & 562500 & 929653 & 432045 \\
\hline 5 & 5237973 & 841265 & 1395299 & 650437 \\
\hline 6 & 7584341 & 1146456 & 1878191 & 852224 \\
\hline 7 & 9387487 & 1371404 & 2288539 & 1075632 \\
\hline 8 & 11332103 & 1625525 & 2770639 & 1265632 \\
\hline Corr & & & & \\
Coeff & 0.999573127 & 0.999430855 & 0.999887919 & 0.999841104 \\
value & & & & 169230 \\
\hline Slope & 25152 & 109655 & 73756 & 8268 \\
\hline Intercept & 40131 & 8166 & 6364 & \\
\hline
\end{tabular}

Table 1: Linearity Results of Canagliflozin, Dapagliflozin, Empagliflozin and Ertugliflozin.

\begin{tabular}{|l|c|c|c|c|}
\hline $\begin{array}{l}\text { Spiked Conc } \\
(\mu \mathrm{g} / \mathrm{ml})\end{array}$ & $\begin{array}{c}\text { Canagliflozin } \\
\text { mean peak area } \pm \text { SD (\% } \\
\text { RSD) }\end{array}$ & $\begin{array}{c}\text { Dean peak area } \pm \text { SD (\% } \\
\text { RSD) }\end{array}$ & $\begin{array}{c}\text { Empagliflozin } \\
\text { mean peak area } \pm \text { SD (\% } \\
\text { RSD) }\end{array}$ & $\begin{array}{c}\text { mean peak area } \pm \text { SD (\% } \\
\text { RSD) }\end{array}$ \\
\hline $50 \%$ & $3790076 \pm 15551(0.41)$ & $559896 \pm 2216(0.40)$ & $923267 \pm 14831(1.61)$ & $428419 \pm 2238(0.52)$ \\
\hline $100 \%$ & $7593835 \pm 10633(0.14)$ & $1123366 \pm 11069(0.99)$ & $1843084 \pm 14566(0.79)$ & $853104 \pm 1693(0.20)$ \\
\hline $150 \%$ & $11380904 \pm 73561(0.65)$ & $1669808 \pm 21293(1.28)$ & $2767665 \pm 19470(0.70)$ & $1276287 \pm 11342(0.89)$ \\
\hline
\end{tabular}

Table 2A: Recovery studies values of Empagliflozin.

Mean of three replicates

Precision

Intermediate Precision and Method precision of gliflozin derivatives such as Canagliflozin Dapagliflozin, Empagliflozin and Ertugli- flozin was calculated by injecting 300,10, 25 and $5 \mu \mathrm{g} / \mathrm{mL}$ samples of triplicate solution into HPLC system respectively, the obtained results were found to be more precise. The \% RSD of both the methods was found 0.16 to 0.91 indicates that the method was precise and reproducible.

\begin{tabular}{|l|c|c|c|c|c|c|c|c|}
\hline \multirow{2}{*}{ S. No } & \multicolumn{2}{|c|}{ Canagliflozin } & \multicolumn{2}{c|}{ Dapagliflozin } & \multicolumn{2}{c|}{ Empagliflozin } & \multicolumn{2}{c|}{ Ertugliflozin } \\
\cline { 2 - 9 } & Inter & Method & Inter & Method & Inter & Method & Inter & Method \\
\hline 1 & 7591234 & 7559274 & 1113125 & 1101286 & 1854786 & 1855679 & 850430 & 852319 \\
\hline 2 & 7571328 & 7599553 & 1115871 & 1120871 & 1872367 & 1872432 & 855320 & 853247 \\
\hline 3 & 7541384 & 7544189 & 1127154 & 1112783 & 1841542 & 1833387 & 853461 & 851054 \\
\hline
\end{tabular}


Simultaneous Estimation of Gliflozin Derivatives Canagliflozin, Dapagliflozin, Empagliflozin and Ertugliflozin Using RP-HPLC Methods

\begin{tabular}{|l|c|c|c|c|c|c|c|c|}
\hline 4 & 7523784 & 7585510 & 1116245 & 1106874 & 1835143 & 1827485 & 852312 & 855138 \\
\hline 5 & 7583128 & 7574115 & 1116871 & 1117136 & 1846357 & 1842066 & 855761 & 852055 \\
\hline 6 & 7513354 & 7583067 & 1127652 & 1121784 & 1882687 & 1861679 & 853124 & 851359 \\
\hline Mean & 7554035 & 7574285 & 1119486 & 1113456 & 1855480 & 1848788 & 853401 & 852529 \\
\hline SD & 29607 & 18132 & 5721 & 7414 & 16916 & 15858 & 1796 & 1362 \\
\hline$\%$ RSD & 0.39 & 0.24 & 0.51 & 0.67 & 0.91 & 0.86 & 0.21 & 0.16 \\
\hline
\end{tabular}

Table 2 B: Intermediate and Method Precision studies of Empagliflozin.

Mean of three replicates

Robustness

Deliberate changes in validation parameters didn't alter the robustness of the developed method. Robustness value for different parameters like Flow rate, Temperature and Mobile phase were summarized in table 3 . The $\%$ RSD was found to be less than $02 \%$ for Empagliflozin and no significant changes in the entire procedure which indicates the method is Robust.

\begin{tabular}{|c|c|c|c|c|c|c|}
\hline \multirow{2}{*}{ S. No } & \multirow{2}{*}{ Parameters } & \multirow{2}{*}{ Condition } & \multicolumn{4}{|c|}{ Mean peak area \pm SD $(\% \mathrm{RSD})$} \\
\hline & & & Canagliflozin & Dapagliflozin & Empagliflozin & Ertugliflozin \\
\hline 1 & Flow rate Minus & $(0.8 \mathrm{ml} / \mathrm{min})$ & $\begin{array}{c}7255060 \pm 10163 \\
(0.14)\end{array}$ & $\begin{array}{c}10555363 \pm 12434 \\
(1.18)\end{array}$ & $\begin{array}{c}1646629 \pm 18567 \\
(1.13)\end{array}$ & $\begin{array}{c}802784 \pm 1370 \\
(0.17)\end{array}$ \\
\hline 2 & Flow rate Plus & $(1.2 \mathrm{ml} / \mathrm{min})$ & $\begin{array}{c}7756051 \pm 22941 \\
(0.3)\end{array}$ & $\begin{array}{c}1749673 \pm 15198 \\
(0.87)\end{array}$ & $\begin{array}{c}1968917 \pm 26790 \\
(1.36)\end{array}$ & $\begin{array}{c}896526 \pm 2001 \\
(0.22)\end{array}$ \\
\hline 3 & $\begin{array}{l}\text { Mobile phase } \\
\text { Minus }\end{array}$ & $(48: 52)$ & $\begin{array}{c}7372226 \pm 19610 \\
(0.27)\end{array}$ & $\begin{array}{c}949916 \pm 8471 \\
(0.89)\end{array}$ & $\begin{array}{c}1562673 \pm 13471 \\
(0.86)\end{array}$ & $\begin{array}{c}845500 \pm \\
1781(0.21)\end{array}$ \\
\hline 4 & Mobile phase Plus & $(52: 48)$ & $\begin{array}{c}7955559 \pm 44866 \\
(0.56)\end{array}$ & $\begin{array}{c}1562110 \pm 15315 \\
(0.98)\end{array}$ & $\begin{array}{c}2169657 \pm 16777 \\
(0.77)\end{array}$ & $\begin{array}{c}875669 \pm 2161 \\
(0.25)\end{array}$ \\
\hline
\end{tabular}

Table 3: Result of Robustness Method.

\section{Mean of three replicates}

\section{Limit of detection and limit of quantification}

The limit of Detection (LOD) and Limit of quantification (LOQ) for gliflozin derivatives was found to be $10.2 \mu \mathrm{g} / \mathrm{mL}$ and $30 \mu \mathrm{g} / \mathrm{mL}$ for Canagliflozin, $0.3 \mu \mathrm{g} / \mathrm{mL}$ and $1 \mu \mathrm{g} / \mathrm{mL}$ for Dapagliflozin, $0.85 \mu \mathrm{g} /$ $\mathrm{mL}$ and $2.5 \mu \mathrm{g} / \mathrm{mL}$ for Empagliflozin and $0.17 \mu \mathrm{g} / \mathrm{mL}$ and $0.50 \mu \mathrm{g} /$ $\mathrm{mL}$ for Ertugliflozin respectively. The very lowest value obtained by this method indicates the developed method was more precise and reproducible.

\section{Analysis of marketed formulation}

The percentage purity of the six replicate samples found to be within the limit and the amount recovered for the assay method found to be $297.9 \mathrm{mg}, 10.13 \mathrm{mg}, 25.02 \mathrm{mg}$, and $5.04 \mathrm{mg}$ for Cana- gliflozin, Dapagliflozin, Empagliflozin and Ertugliflozin respectively and the \% purity was reported between 99.3 - 101.3. Reported $\%$ purity of gliflozin derivatives found within the limit as per pharmacopeia.

\begin{tabular}{|l|c|c|c|}
\hline Drug & $\begin{array}{c}\text { Labeled claim } \\
\text { (mg) }\end{array}$ & $\begin{array}{c}\text { Amount found * } \\
\text { (mg) }\end{array}$ & $\begin{array}{c}\text { Recovery * } \\
\text { (\%) }\end{array}$ \\
\hline Canagliflozin & 300 & 297.9 & 99.3 \\
\hline Dapagliflozin & 10 & 10.13 & 101.3 \\
\hline Empagliflozin & 25 & 25.02 & 100.1 \\
\hline Ertugliflozin & 5 & 5.04 & 100.8 \\
\hline
\end{tabular}

Table 4: Assay estimation of Empagliflozin. 
Mean of three replicates

\section{Stress degradation studies}

Stress degradation studies conducted as per the ICH guidelines and the drug few gliflozin derivatives doesn't degrade in acidic, thermal, and photolytic method whereas the some of it degrades in presence of basic and oxidative hydrolysis process (Figure 4). Amount of degraded drug products recovered in acidic, basic, oxidative, Thermal and Photolytic conditions were found less than $8 \%$ in $0.1 \mathrm{~N}$ conditions and less than $20 \%$ for $1 \mathrm{~N}$ stress conditions summarized and reported in table 5 .

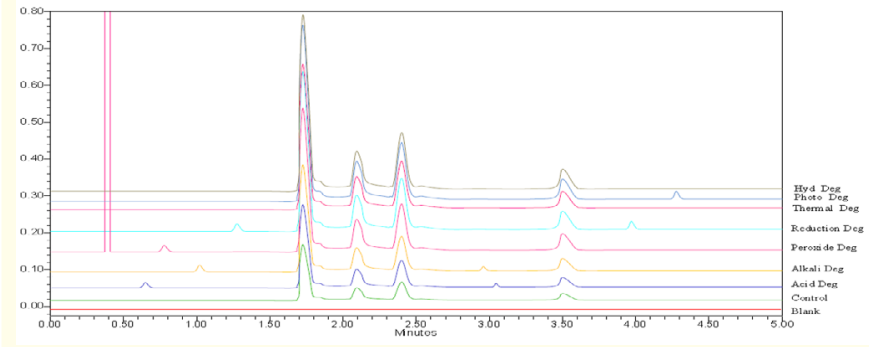

Figure 4: Chromatogram peaks of Canagliflozin, Dapagliflozin, Empagliflozin and Ertugliflozin (L to R) in Forced degradation Studies A-Blank, B-Control, C-Acidic, D-Alkaline, E-Peroxide,

F-Reduction, G-Thermal degradation, H-Photolytic and I-Hydrolysis degradation.

\begin{tabular}{|c|c|c|c|c|c|}
\hline \multirow{2}{*}{ Degradation Type } & \multirow{2}{*}{ Degradation condition } & \multicolumn{4}{|c|}{ Drug recovered (\%) } \\
\hline & & Canagliflozin & Dapagliflozin & Empagliflozin & Ertugliflozin \\
\hline \multirow{2}{*}{ Acid Degradation } & $0.1 \mathrm{~N} \mathrm{HCl}, 15 \mathrm{~min} ., 25^{\circ} \mathrm{C}$ & 98.2 & 98.7 & 98 & 97.8 \\
\hline & $01 \mathrm{~N} \mathrm{HCl}, 15$ min., $25^{\circ} \mathrm{C}$ & 85.6 & 87.5 & 83.9 & 86.4 \\
\hline \multirow{2}{*}{ Alkaline Degradation } & $0.1 \mathrm{~N} \mathrm{NaOH}, 15$ min., $25^{\circ} \mathrm{C}$ & 97.8 & 97.9 & 96.9 & 98.5 \\
\hline & $01 \mathrm{~N} \mathrm{NaOH}, 15$ min., $25^{\circ} \mathrm{C}$ & 84.8 & 88.4 & 86.1 & 85.2 \\
\hline \multirow{2}{*}{ Oxidative Degradation } & $10 \% \mathrm{H}_{2} \mathrm{O}_{2}, 15$ min., $25^{\circ} \mathrm{C}$ & 96.5 & 97.4 & 95.2 & 97.4 \\
\hline & $30 \% \mathrm{H}_{2} \mathrm{O}_{2}, 15 \mathrm{~min} ., 25^{\circ} \mathrm{C}$ & 87 & 89.3 & 88.9 & 83.9 \\
\hline \multirow{2}{*}{ Hydrolysis Degradation } & $5 \mathrm{ml} \mathrm{H}_{2} \mathrm{O}, 5 \mathrm{~min} ., 25^{\circ} \mathrm{C}$ & 99.9 & 99.6 & 99.5 & 99.3 \\
\hline & $10 \mathrm{ml} \mathrm{H}_{2} \mathrm{O}, 5 \mathrm{~min} ., 25^{\circ} \mathrm{C}$ & 98.9 & 98 & 99.1 & 97.4 \\
\hline \multirow{2}{*}{ Reduction Degradation } & $10 \% \mathrm{NaHSO}_{4}, 15$ min., $25^{\circ} \mathrm{C}$ & 97.2 & 95.4 & 96.6 & 96.1 \\
\hline & $30 \% \mathrm{NaHSO}_{4}, 15 \mathrm{~min} ., 25^{\circ} \mathrm{C}$ & 83.7 & 85.8 & 88 & 81.5 \\
\hline \multirow{2}{*}{ Thermal Degradation } & $105^{\circ} \mathrm{C}$ for $3 \mathrm{hrs}$ & 99.2 & 97.2 & 97.1 & 98.4 \\
\hline & $105^{\circ} \mathrm{C}$ for $6 \mathrm{hrs}$ & 99.3 & 97.6 & 97.2 & 98.4 \\
\hline \multirow{2}{*}{ Photolytic degradation } & $3 \mathrm{hrs}$ & 99.2 & 97.2 & 97.1 & 98.4 \\
\hline & $6 \mathrm{hrs}$ & 88.8 & 84.7 & 89.7 & 87.8 \\
\hline
\end{tabular}

Table 5: Data of Stress degradation studies Empagliflozin.

\section{Conclusion}

Our research work on gliflozin derivatives found promising in all parameters in eluting the analyte in very less time and low organic solvent consumptions. Individual methods were developed and reported for Canagliflozin, Dapagliflozin, Empagliflozin and Er- tugliflozin [24]. Intraday precision and Interday precision \% RSD values indicates the designed method has less than $2 \%$ RSD value without any significant variable changes. In Linearity regression method the peak area increases with the increasing concentration of sample and found linear towards the drug concentration. Our 
method can perform estimation of gliflozin derivatives in different laboratory conditions and different analytical conditions. Degradation studies practically proved that weakly ionizable flozin derivatives of few drugs can alter its nature in stress conditions such as basic and oxidative conditions whereas remain stable in those conditions too. Altering forced degradation studies may be useful in identifying the various degraded products and can be analyzed further by using the LCMS method. This simplified method consumes less organic solvent and at the same time it elutes the analyte within a short period of time.

\section{Acknowledgment}

The authors felt grateful and acknowledge the support received from Anjuman-I-Islam Kalsekar Technical Campus School of Pharmacy for allowing us to handle our laboratory works.

\section{Conflict of Interest}

Author declares No conflict of interest for this research work.

\section{Bibliography}

1. Misra M. "SGLT2 inhibitors: a promising new therapeutic option for treatment of type 2 diabetes mellitus". Journal of Pharmacy and Pharmacology 65.3 (2013): 317-327.

2. Wright EM and Turk E. "The sodium/glucose co-transport family SLC5”. Pflügers Archiv 447.5 (2014): 510-518.

3. Harsharan PS., et al. "Sodium Glucose Co-Transporters-2 (SGLT2) Inhibitors as a New Class of Anti-diabetic Drugs: Pharmacokinetics, Efficacy and Clinical Significance". International Journal of Pharmaceutical Science Review and Research 33.1 (2015): 40-47.

4. Nair S and Wilding JP. "Sodium glucose co-transporter 2 inhibitors as a new treatment for diabetes mellitus". Journal of Clinical Endocrinology and Metabolism 95.1 (2010): 34-42.

5. https://go.drugbank.com/drugs/DB08907

6. https://go.drugbank.com/drugs/DB06292

7. https://go.drugbank.com/drugs/DB09038

8. https://go.drugbank.com/drugs/DB11827

9. Aris Liakos., et al. "Canagliflozin for Type 2 diabetes: An upto-date evidence summary". Diabetes Management 5.2 (2015): 119-125.
10. Davida Kruger and Virginia Valentine. "Canagliflozin for the Treatment of Diabetic Kidney Disease and Implications for Clinical Practice: A Narrative Review". Diabetes Therapy 11 (2020): 1237-1250.

11. Sarah L Anderson "Dapagliflozin efficacy and safety: a perspective review". Therapeutic Advances in Drug Safety 5.6 (2014) 242-254.

12. Nareen Krishna Polavarapu., et al. "Dapagliflozin in Clinical Practice - Benefits beyond Glycemic Control. An Expert Review from India”. International Journal of Diabetes 2.1 (2021): 76-90

13. Ajay chadeve. "A review on pharmacology and therapeutic effects of Empagliflozin in patients with type 2 diabetes mellitus". Asian Journal of Pharmaceutical and Clinical Research 13.5 (2020): 16-21.

14. Matthew J Levine. "Empagliflozin for Type 2 Diabetes Mellitus: An Overview of Phase 3 Clinical Trials". Current Diabetes Review 13 (2017): 405-423.

15. Vivianne K Nguyen., et al. "Overview of Ertugliflozin". Clinical Pharmacology Update (2018).

16. Jie Liu., et al. "Efficacy of Ertugliflozin in monotherapy or combination therapy in patients with type 2 diabetes: A pooled analysis of placebo-controlled studies". Diabetes and Vascular Disease Research 16.5 (2019): 415-423.

17. Shahzad Sharif., et al. "Stability Indicating, $\mathrm{pH}$ and $\mathrm{pKa}$ Dependent HPLC-DAD Method for the Simultaneous Determination of Weakly Ionizable Empagliflozin, Dapagliflozin and Canagliflozin in Pharmaceutical Formulations". Chromatographia (2020).

18. Hadir M., et al. "Stability-indicating capillary electrophoresis method for the simultaneous determination of Metformin hydrochloride, Saxagliptin hydrochloride, and Dapagliflozin in pharmaceutical tablets". Journal of Liquid Chromatography and Related Technologies ISSN 1082-6076 (2019).

19. Sonia T., et al. "Validated Liquid Chromatographic Method for the Determination of (Canagliflozin, Dapagliflozin or Empagliflozin) and Metformin in the Presence of (1-Cyanoguanidine)". Journal of Chromatographic Science 1-11 (2018).

20. Mohini A., et al. "Development and validation of analytical LCMS method for simultaneous determination of oral hypoglycemic agents (MET, DFZ, EFZ and CFZ) in pharmaceutical dosage form". World Journal of Pharmaceutical Research 10.6 (2021): 1380-1393. 
21. Bruna Carolina Lui Dias., et al. "A new HPLC-MS/MS method for the simultaneous quantification of SGLT2 inhibitors and Metformin in plasma and its application to a pharmacokinetic study in healthy volunteers". Biomedical Chromatography 33 (2019): e4663.

22. ICH guideline Q1A (R2). "Stability testing of new drug substances and products". ICH (2003).

23. ICH guideline Q2 (R1). "Validation of Analytical Procedures: Text and Methodology". ICH (2005).

24. Murugesan A and Mathrusri Annapurna M. "Validated and quantified stability indicating stress degradation study of oral anti-diabetic agent Canagliflozin by RP-HPLC method". International Journal of Applied Pharmaceutics 13.5 (2021): 358363.

\section{Assets from publication with us}

- Prompt Acknowledgement after receiving the article

- Thorough Double blinded peer review

- Rapid Publication

- Issue of Publication Certificate

- High visibility of your Published work

Website: www.actascientific.com/

Submit Article: www.actascientific.com/submission.php

Email us: editor@actascientific.com

Contact us: +919182824667

Citation: Arulselvan Murugesan and Annapurna Mukthinuthalapati Mathrusri. "Simultaneous Estimation of Gliflozin Derivatives Canagliflozin, Dapagliflozin, Empagliflozin and Ertugliflozin Using RP-HPLC Methods". Acta Scientific Pharmaceutical Sciences 6.1 (2022): 03-12. 